\title{
Impact of supply problems of preservative-free glaucoma medications on patients and hospital staff
}

\begin{tabular}{|r|l|}
\hline Journal: & Ophthalmic and Physiological Optics \\
\hline Manuscript ID: & OPO-OA-1389 \\
\hline Manuscript Type: & Original Article \\
\hline Date Submitted by the Author: & 27-Jul-2014 \\
\hline Complete List of Authors: & $\begin{array}{l}\text { Shah, Shima; Moorfields Eye Hospital, Optometry Department } \\
\text { Theodossiades, Julia; Moorfields Eye Hospital, Optometry Department } \\
\text { Chapman, Kristin; Moorfields Eye Hospital, Pharmacy } \\
\text { Murdoch, Ian; Institute of Ophthalmology, ; Moorfields Eye Hospital, } \\
\text { Glaucoma Service }\end{array}$ \\
\hline Keywords: & Glaucoma, Drug supply, Medicines supply, preservative free drops \\
\hline & \\
\hline
\end{tabular}

SCHOLARONE

Manuscripts 
1

2

3

4

5

6

7

8

9

10

11

12

13

14

15

16

17

18

19

20

21

22

23

24

25

26

27

28

29

30

31

32

33

34

35

36

37

38

39

40

41

42

43

44

45

46

47

48

49

50

51

52

53

54

55

56

57

58

59

60

\title{
Impact of supply problems of preservative-free glaucoma medications on patients and hospital staff
}

\author{
Shima Shah ${ }^{1}$, Julia Theodossiades ${ }^{1}$, Kristin Chapman ${ }^{1}$, Ian Murdoch ${ }^{1,2}$ \\ ${ }^{1}$ Moorfields Eye Hospital, London, UK, ${ }^{2}$ Institute of Ophthalmology, London, UK
}

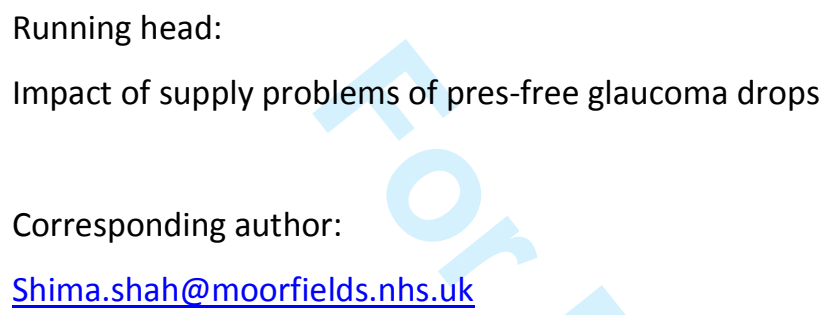

Running head:

Impact of supply problems of pres-free glaucoma drops

Corresponding author:

Shima.shah@moorfields.nhs.uk

Keywords:

Glaucoma, drug supply, medicines supply, preservative free drops

Disclosure:

The authors report no conflicts of interest and have no proprietary interest in any of the materials mentioned in this article.

Acknowledgments:

This research received no specific grant from any funding agency in the public, commercial, or notfor-profit sectors. 
Abstract:

Glaucoma is a chronic ocular disease, which is usually managed with long-term medical therapy, in the form of eye drops. Patients intolerant to preservatives in topical medicines, require preservativefree versions. From early 2011 patients attending Moorfields Eye Hospital (MEH), London, started to report recurring problems with the supply of the preservative-free (PF) glaucoma medications Timolol, Cosopt and Trusopt. This study investigates the impact of the supply problems of these medications at MEH from a patient, administrative and clinical perspective. Information was sought by interviewing both patients and hospital staff, and a retrospective case note review between April 2010 and May 2013.

Many hospital roles, both administrative and clinical, were involved in attempting to resolve the impact of the supply problems. All staff reported a considerable increase in their workload. At the peak of the problem the glaucoma secretaries received about 150 enquiries per week. Notes were retrieved for 83 (66\%) of a random sample of 125 patients. The patient notes review showed that $22 \%$ encountered a supply problem. Of these, over a third attended MEH A\&E for repeat supplies and $89 \%$ eventually had their medication changed. $39(78 \%)$ of a random sample of 50 patients were interviewed by telephone. $59 \%$ reported a supply problem. Of these, a third attended MEH A\&E for repeat supplies and a half eventually required an alternative medication. Patients mentioned going to considerable lengths in their attempts to obtain ongoing supplies in the community.

This study shows that medication supply problems can have a major impact on patients and hospital services. Drug supply problems occur across many fields of medicine and with increasing frequency. The findings of this study highlight the importance of early communication of impending shortages between manufacturers and the Department of Health, as recommended in the best practice guidelines $^{3,4}$. However, in order to minimize the impact of medication shortages on patients, clinicians and administrative staff, hospitals and health workers, need immediate notification of potential supply problems. 
Introduction:

Glaucoma is a chronic ocular disease, which is usually managed with long-term medical therapy in the form of eye drops. The majority of glaucoma eye drops contain preservatives which maintain the sterility of drops and aid penetration of the active agents into the anterior chamber. However, some patients are intolerant to preservatives and require preservative-free medications ${ }^{1}$. From early 2011 , patients started to experience recurring problems with the supply of the preservative-free (PF) glaucoma medications Timolol, Cosopt and Trusopt. This study investigates the impact of the supply problems of the above PF glaucoma medications at Moorfields Eye Hospital (MEH) from a patient, administrative and clinical perspective.

\section{Methods:}

Three sources of information were sought to assess the impact of supply problems: -

\section{Anecdotal staff report}

Glaucoma consultants, A\&E consultants, glaucoma secretaries, glaucoma clerks, patient advice and liaison officers (PALS), Moorfields Direct (telephone help line for patients) and pharmacists (medicines information service and dispensary) were interviewed. An estimate of the peak number of enquiries received per week regarding this problem was sought together with anecdotes of consequences of supply problems.

\section{Patient notes assessment}

The patient ID numbers of new adult prescriptions of PF Timolol 0.25\%, Cosopt and Trusopt were determined from the Moorfields Eye Hospital (MEH) pharmaceutical database for the year April 2010 to March 2011. A random sample of 125 patients was taken from the total number of patients issued new prescriptions. Their notes were reviewed from April 2010 to May 2013 using a standardized proforma. This data collection period predated the start of the supply problems. Reviewing their notes to present day covered the period of maximum drug supply disruption. Thus patients on these drops at the time of the supply problems were maximally targeted for this study. Data was collected concerning evidence of supply problems, management change, increased hospital visits and additional correspondence. 


\section{Patient interview}

Of the notes that were reviewed (patient notes assessment), the first 50 patients were additionally contacted by telephone. Their experience concerning ongoing and regular drug supply was sought. Where there had been difficulties further questions were asked regarding attempts to overcome the problem and consequences. A supply problem was defined as inability to obtain or having to wait more than two weeks to receive the drop.

\section{Results:}

\section{Anecdotal staff report}

Many hospital employees (including glaucoma clerks, glaucoma secretaries, Moorfields Direct, PALS and pharmacists) were involved in attempting to resolve the supply difficulties encountered by patients. Although the number of enquiries varied by role, all staff noted a considerable impact on their workload. The largest load fell upon the glaucoma clerks and the secretaries who, at the peak of the problem, received about 200 and 150 enquiries a week respectively. Typically the secretaries had to request patient notes from medical records and seek a medical opinion, which in turn generated correspondence with the GP and the patient.

Seven of the $10 \mathrm{MEH}$ pharmacists responded. Of these, five reported receiving up to 5 enquiries per week, one received 15 a week, and one in Medicines Information (telephone advisory service) reported up to 50 a week. The pharmacists then sought medical advice from the glaucoma service. MEH Pharmacists also reported patients were confused, distressed, frustrated and angry about the situation and anxious about reactions to alternative drops.

The lower peak of enquiries reported by consultants may represent a resolution of a proportion of the enquiries by other medical staff (fellows and registrars), who were not sampled in the study. 
Table 1: Enquiries received by staff at $\mathrm{MEH}$

\begin{tabular}{llll}
\hline Staff report & Sample & Responded (\%) & Total enquiries per week \\
\hline Secretaries & 4 & $4(100)$ & 150 \\
\hline PALS & 2 & $2(100)$ & 15 \\
\hline Moorfields Direct & 2 & $2(100)$ & 20 \\
\hline Glaucoma clerks & 13 & $9(69)$ & 200 \\
\hline Pharmacists & 10 & $7(70)$ & 85 \\
\hline Consultants & 22 & $19(82)$ & 50 \\
\hline TOTAL & & & $\mathbf{5 2 0}$ \\
\hline
\end{tabular}

\section{Patient notes assessment}

During the year April 2010 to March 2011, 328 new prescriptions were issued to 301 patients. Some received dual therapy. 191 received PF Cosopt, 63 PF Trusopt, 73 PF Timolol 0.25\% and one PF Timolol $0.5 \%$. Notes were retrieved for $83(66 \%)$ of the random sample of 125 patients. A total of 93 prescriptions were issued to these 83 patients; 59 for PF Cosopt, 15 for PF Trusopt, 18 for PF Timolol 0.25\% and 1 for PF Timolol 0.5\%.

- Supply problems where unambiguously stated in the notes for $18 / 83(22 \%)$ patients.

- Patient management impact $89 \%(16 / 18)$ of patients with supply problems required a management change; 15 had a topical therapy change and one was listed for trabeculectomy surgery. The remaining two patients had obtained repeat supplies from the hospital (A\&E).

- Patient and Service impact More than a third (39\%) of those with supply problems had attended A\&E for repeat supplies and/or advice, some on multiple occasions. 7 of the 18 patients with supply problems made ten additional visits to hospital. Nine of these visits were to $A \& E$ and one was to the glaucoma clinic. 
Figure 1: Summary of patient notes assessment

327 new therapy PF drops

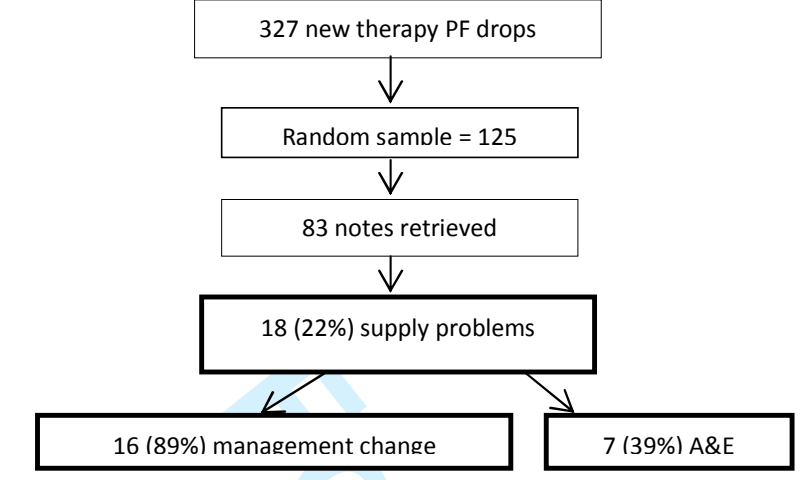

$7 / 18$ patients with supply problems generated 10 episodes of contact to $\mathrm{MEH}$

\section{Patient Interview}

It was possible to speak to 39 of the 50 patients telephoned.

- Supply problems were reported by $23 / 39(59 \%)$ of patients.

- Patient management impact

$52 \%(12 / 23)$ of patients with supply problems required a change in topical therapy.

- Patient and Service impact

Nearly a third (30\%) of those with supply problems attended A\&E for repeat supplies and/or advice, some on multiple occasions. 13 of 23 reporting supply problems contacted the hospital on 22 occasions. These comprised of 10 visits (7 patients) to A\&E, 6 visits (4 patients) to pharmacy and 6 telephone calls (6 patients) to MEH.

Figure 2: Summary of patient interview

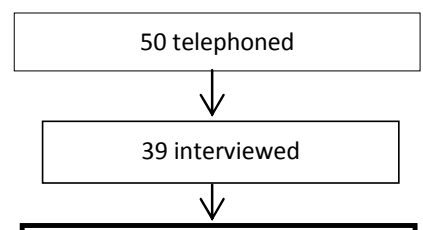

23 supply problems (59\%)

$12(52 \%)$ management change

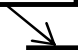

$7(30 \%) A \& E$

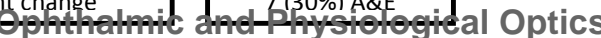

$13 / 23$ patients with supplv problems generated 22 episodes of contact to MEH 
Patient Interview Anecdotes

Some patients said they travelled long distances to obtain supplies and community pharmacists reported having to telephone colleagues in the area to seek out supplies. Here is a sample of the anecdotes collected:

- "I was really anxious. The patients should have had some warning."

- “I couldn't get my drops from my local pharmacy. My husband contacted MEH pharmacy and came up and collected a supply. I had problems when this ran out so my husband then contacted the manufacturer who then contacted the wholesaler. The wholesaler arranged for supplies to be sent to my local pharmacist, who now orders well in advance."

- "My local pharmacy can't get my drop so I have to take a long bus ride to one that's quite far away."

- "I called all my local pharmacies. I found one five miles away with a one month supply. When this ran out I attended A\&E"

- "My pharmacist obtained supplies from pharmacists in the area. When he eventually couldn't get any more I came into A\&E and 'they' changed my drop to Betagan."

Table 2: Summary of supply problems and their consequence, as stated in patients' notes and patient interview

\begin{tabular}{|c|c|c|c|c|c|}
\hline & Sample & Responded (\%) & $\begin{array}{c}\text { Supply problems } \\
\text { (\%) }\end{array}$ & A\&E (\%) & $\begin{array}{c}\text { Management } \\
\text { Change (\%) }\end{array}$ \\
\hline $\begin{array}{l}\text { Patient notes } \\
\text { assessment }\end{array}$ & 125 & $83(66)$ & $18(22)$ & $7 / 18$ (39) & $16 / 18(89)$ \\
\hline Patient interview & 50 & $39(78)$ & $23(59)$ & $7 / 23(30)$ & $12 / 23(52)$ \\
\hline
\end{tabular}




\section{Discussion:}

To our knowledge, this represents the first report of the impact of supply problems of topical medication in the field of glaucoma. The study found these problems had a considerable impact on patients both in terms of seeking ongoing supplies and requiring changes in management. This study also shows erratic supply of medication increased the workload of all patient contact points in the hospital.

The study only sampled patients receiving new prescriptions of the PF medications and only patients identified for the year April 2010 to March 2011. The total number of patients using these PF medications, including long standing users, during this period, would have been considerably larger. This study may, therefore, underestimate the impact of the erratic drug supply on patients and hospital services.

Assessment of patients' notes revealed $22 \%$ of patients had supply problems, compared with $59 \%$ for those patients interviewed. The lower figure for supply may be due to underreporting by patients in clinic and/or under recording of the situation by clinicians in the notes. Of the $22 \%$ with supply problems (patients' notes assessment), $89 \%$ required a management change. Of the $59 \%$ with supply problems (patients' interviewed), 52\% required a management change. The $89 \%$ may be a misleadingly high figure, resulting from underreporting of supply problems in the patient notes, whilst the $52 \%$ may be a misleadingly low figure as a result of discrepancies in recollection of management changes by patients.

Those who had no supply problems were generally either only on the drug for a short period of time, regularly visited the hospital and obtained repeat drug supplies from the hospital, or managed to get supplies locally.

Assessment of both patients' notes and interviews revealed that approximately a third with supply problems attended $A \& E$, some on multiple occasions, to obtain further supplies or an alternative medical solution. This is likely an underestimate, as not all A\&E entries are filed in patient records. This would have been inconvenient and time consuming for patients and staff.

This study did not investigate cost implications to the Trust. 


\section{Conclusions:}

Glaucoma is a chronic disease that requires long-term medical therapy. Our results show that medication supply problems can have a major impact on patients and hospital services.

The findings of this study highlight the importance of early communication of impending shortages between manufacturers and the Department of Health, as recommended in the best practice guidelines $^{3,4}$. However, this information also needs to be available to health workers in direct contact with patients as soon as possible.

In order to minimize the impact of medication shortages on patients, clinicians and administrative staff, hospitals need immediate notification of potential supply problems. 


\section{References:}

1. Hopes M and Broadway D, Preservative-free Treatment in Glaucoma is a Sensible and Realistic Aim for the Future, European Ophthalmic Review, 2010; 23-28

2. Directive 2001/83/EC of the European Parliament http://ec.europa.eu/health/files/eudralex/vol1/dir 200183 cons/dir2001 83 cons 20081230 en.pdf (accessed 27/4/13)

3. Joint Department of Health and Association of the British Pharmaceutical Industry Guidance. Notification and management of medicines shortages, Best Practice Guidelines. (Dec 2006) Available at: https://www.gov.uk/government/uploads/system/uploads/attachment data/file/237064/d h 063441.pdf (accessed 19/06/14)

4. Joint Department of Health and British Generic Manufacturers Association Guidance. Notification and management of medicines shortages, Best Practice Guidelines. (Dec 2006) Available at:

https://www.gov.uk/government/uploads/system/uploads/attachment data/file/237071/d h 063440 1.pdf (accessed 19/06/14) 